\title{
Implication of HYBID (Hyaluronan-Binding Protein Involved in Hyaluronan Depolymerization) in Hyaluronan Degradation by Synovial Fibroblasts in Patients with Knee 0steoarthritis

Jun Shiozawa, ${ }^{* \dagger}$ Susana de Vega, ${ }^{*}$ Mehmet Z. Cilek, ${ }^{*}$ Chiho Yoshinaga, ${ }^{*}$ Tomomi Nakamura, ${ }^{\S}$ Shinya Kasamatsu, Hiroyuki Yoshida, ${ }^{\S}$ Haruka Kaneko, ${ }^{\dagger}$ Muneaki Ishijima, ${ }^{* \dagger \dagger}$ Kazuo Kaneko, ${ }^{* \dagger}$ and Yasunori Okada*

From the Departments of Pathophysiology for Locomotive and Neoplastic Diseases* and Medicine for Orthopaedics and Motor Organ, ${ }^{\dagger}$ Juntendo University Graduate School of Medicine, Tokyo; the Sportology Center, ${ }^{\ddagger}$ Juntendo University, Tokyo, Japan; and Biological Science Research, ${ }^{\S}$ Kao Corporation, Odawara-shi, Japan

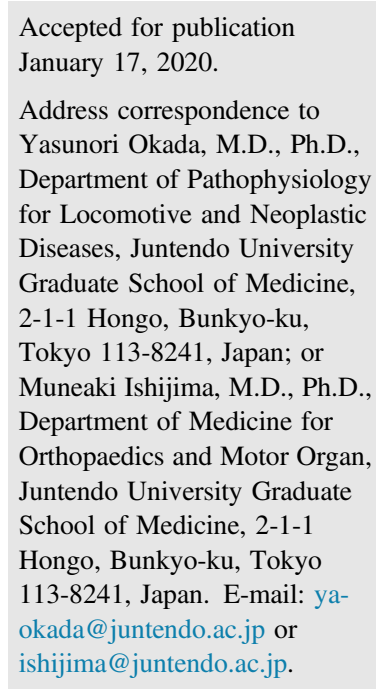

\begin{abstract}
Cell migration-inducing hyaluronidase 1 (CEMIP), also known as hyaluronan (HA)-binding protein involved in HA depolymerization (HYBID), plays a role in HA degradation. CEMIP2, also known as transmembrane protein 2 (TMEM2), possessing a sequence similarity with HYBID, is reported as a hyaluronidase in mice. However, the expression of these molecules in osteoarthritic synovium and their involvement in $\mathrm{HA}$ degradation in synovial fluid (SF) from patients with knee osteoarthritis remain elusive. This study examined their expression in synovial tissue and the relationship with molecular weight of HA in SF in knee osteoarthritis patients. Quantification of mRNA demonstrated that HYBID expression is significantly (5.5-fold) higher in osteoarthritic synovium than in normal control synovium, whereas TMEM2 expression level is similar between the two groups. By immunohistochemistry, HYBID was localized mainly to CD68negative and fibroblast-specific protein 1-positive synovial lining cells and sublining fibroblasts in osteoarthritic synovium. The mRNA expression levels of HYBID, but not TMEM2, in osteoarthritic synovium positively correlated with distribution of lower-molecular-weight HA with below $1000 \mathrm{kDa}$ in SF. HA-degrading activity in osteoarthritic synovial fibroblasts was abrogated by siRNA-mediated knockdown of HYBID. Among the 12 factors examined, IL- 6 significantly up-regulated the HYBID expression and HA-degrading activity in osteoarthritic synovial fibroblasts. These data suggest that HYBID overexpressed by IL-6-stimulated synovial fibroblasts is implicated in HA degradation in osteoarthritic synovium. (Am J Pathol 2020, 190: 1046-1058; https://doi.org/10.1016/j.ajpath.2020.01.003)
\end{abstract}

The joint cavity is surrounded by articular cartilage and synovium and filled with synovial fluid, which is a mixture of hyaluronan (HA) and a protein-rich ultrafiltrate of blood plasma. In the normal joint, HA, which is an unbranched nonsulfated glycosaminoglycan composed of repeating disaccharide units of D-glucuronic acid and N-acetyl-Dglucosamine and synthesized by HA synthases (HAS1, HAS2, and HAS3), is present in the range of 1000 to 10,000 $\mathrm{kDa}$, that is, high-molecular-weight HA (HMW-HA). HMW-HA plays an essential role in maintaining the lubricating property and shock absorption function of synovial fluid. $^{1,2}$ These physicochemical properties of HA are lost when it is degraded to lower-molecular-weight HA (LMW-HA). ${ }^{3}$ Other biological activities of HA are also dependent on its molecular weight ${ }^{4,5}$ : HMW-HA is anti-inflammatory and antiangiogenic, whereas LMW-HA promotes inflammatory and angiogenic reactions. ${ }^{6,7}$ In osteoarthritis (OA), HA degradation is enhanced and so

Supported by Japan Society for the Promotion of Science Grant-in-aid for Scientific Research (JSPS KAKENHI) grants 16H05454 (Y.O.), 19H03788 (Y.O.), and 18K09082 (M.I.).

Disclosures: H.Y. is a holder of the HYBID patent (WO2011/ 152071A1). 
LMW-HA is accumulated in synovial fluid. ${ }^{3}$ Therefore, HA in OA synovial fluid may not only enhance mechanical stress on articular cartilage due to decreased shock absorption function, but also promote synovitis, leading to the possible progression of cartilage destruction in the OA joint. Recently, the risk of knee OA progression has been associated with the preponderance of HA below $1000 \mathrm{kDa}$ in synovial fluid, but not average HA molecular weight. ${ }^{8}$

Arthroscopic and histologic studies have shown that synovitis commonly occurs in knee $\mathrm{OA},{ }^{9,10}$ and an immunohistochemical study reported that degree of synovial inflammation is more severe in early-stage knee OA than in late-stage OA. ${ }^{11}$ However, a growing amount of evidence using noninvasive imaging techniques such as magnetic resonance imaging demonstrated that synovial inflammation is present in many patients at all stages of $\mathrm{OA}^{12,13}$ and supports the notion that synovitis contributes to the progression of $\mathrm{OA}$ by accelerating cartilage breakdown. ${ }^{12,14}$ Moreover, recent studies on the risk factors of knee OA have suggested that synovitis may be an independent cause of $\mathrm{OA}^{15}$ and an independent driver of radiographic $\mathrm{OA}$ onset and progression. ${ }^{13}$

Hyaluronidases (HYALs) composed of six different molecules were long thought to be key enzymes for HA degradation, ${ }^{16}$ and among them, HYAL-1 and HYAL-2, the latter of which acts together with cell surface HA receptor CD44, were reported to play a key role in HA degradation. However, knockdown of these genes failed to change HA-degrading activity in skin fibroblasts. ${ }^{17}$ Therefore, we searched for new molecules related to HA degradation by microarray analysis, and demonstrated that hyaluronanbinding protein involved in hyaluronan depolymerization (HYBID), which was renamed later as cell migrationinducing hyaluronidase 1 (CEMIP) by HUGO Gene Nomnclature Committee, plays a key role in HA degradation independently from HYAL1 and HYAL2/CD44 in human fibroblasts. ${ }^{17,18}$ HYBID was reported as a deafness gene of unknown function (KIAA1199) ${ }^{19}$ and also named as CEMIP (cell migration-inducing protein) by another group. ${ }^{20}$ A previous study on skin fibroblasts has shown that HYBID is localized in clasthrin-coated vesicles and contributes to degradation of HMW-HA into LMW-HA fragments, which are released to the extracellular milieu. ${ }^{17}$ HYBID is a secreted protein composed of one G8, two $\mathrm{GG}$, and four $\mathrm{PbH} 1$ domains, lacking substantial homology to HYAL enzymes, HA-binding proteins, and HA-link modules. It selectively binds to HA, but does not interact with sulfated glycosaminoglycans. ${ }^{17}$ A recent study has shown that a type II transmembrane protein with a sequence homology to HYBID, named as transmembrane protein 2 (TMEM2) [alias cell migration-inducing hyaluronidase 2 (CEMIP2)] acts as cell-surface hyaluronidase in mice and is ubiquitously expressed in adult mouse tissues. ${ }^{21}$ However, no studies have shown the expression or function of TMEM2 in human tissues such as synovium. Although it is reported that HYBID is expressed by rheumatoid synovial lining and sublining cells ${ }^{17}$ little information is available for tissue or cellular localization responsible for the expression in OA synovial tissue. In addition, the relationship between the expression levels of HYBID or TMEM2 and the size distribution of HA in OA synovial fluids remains unknown. Recent studies on the regulation of the HYBID gene expression have demonstrated that transforming growth factor- $\beta 1$ (TGF- $\beta 1$ ) down-regulates the expression in skin fibroblasts, ${ }^{18}$ and tumor necrosis factor- $\alpha$ (TNF- $\alpha$ ) upregulates the expression in OA chondrocytes. ${ }^{8}$ However, little is known about regulators of HYBID expression in OA synovial fibroblasts.

The present study found that HYBID, but not TMEM2, is up-regulated in OA synovial tissue. This study also shows that HYBID is implicated in degradation of HMW-HA in OA synovial fluids, and that among the factors examined, IL-6 efficiently up-regulates the HYBID expression in OA synovial fibroblasts.

\section{Materials and Methods}

\section{Clinical Samples and Histology}

Synovial tissue samples were obtained at the time of arthroplasty from joints of patients with knee OA $(n=27$; mean $\pm \mathrm{SD}$ age, $75.7 \pm 7.3$ years), which was diagnosed according to the criteria of the American College of Rheumatology. ${ }^{22}$ Normal control synovial tissue samples were obtained at reconstruction surgery for anterior cruciate ligament from knee joints of patients with anterior cruciate ligament injury ( $n=8$; mean \pm SD age, $37.3 \pm 11.0$ years). The OA synovial tissues were fixed with $4 \%$ paraformaldehyde and embedded in paraffin. Paraffin sections were stained with hematoxylin and eosin. Written informed consent was obtained from the patients for the experimental use of the surgical samples according to the hospital ethics guidelines. The study protocols, which complied with the principles outlined in the Declaration of Helsinki, were approved by the Ethical Committee Review Board in Juntendo University (No 15-074).

\section{Quantification of mRNA Copy Numbers}

Total RNA was isolated from OA and normal control synovial tissues using RNeasy Mini Kit (Qiagen, Hilden, Germany) and cDNA was synthesized from $2 \mu \mathrm{g}$ of total RNA using the ReverTra Ace qPCR RT Master Mix (Toyobo, Osaka, Japan). The cDNA was amplified by quantitative real-time PCR using the THUNDERBIRD SYBR qPCR Mix (Toyobo) on a QuantStudio3 (Applied Biosystems, Foster City, CA). Nucleotide sequences for the primers were as follows: for HYBID 5'-TCACAGAGGACTCCTACCCG-3' (forward) and 5'-ATTGGCCATCCAGAAGGTGG-3' (reverse); and for TMEM2 $5^{\prime}$ TTACGGCTTTCAGGGTGGTC-3' (forward) and $5^{\prime}$ TTGGGAACGTCCTGTTCCTG-3' (reverse). To examine 
the expression levels of HYBID and TMEM2 in synovial tissues, absolute quantification of mRNA copy numbers was performed using the standard curve method according to the methods described by Whelan et al. ${ }^{23}$ Briefly, purified plasmids containing the coding sequences of human HYBID [pcDNA3.1(-)-HYBID $]^{17}$ and human TMEM2 (RC224793; Origene, Rockville, MD) were digested with restriction enzymes, that is, EcoRI and NdeI (TAKARA, Kusatsu, Japan) for the HYBID plasmid and FauI (New England Biolabs, Ipswich, MA) for the TMEM2 plasmid, to cut out the inserts from the plasmids, both of which were purified using the QIAquick Nucleotide Removal Kit (Qiagen). Concentrations of the plasmid and insert were determined using the QuantiFluor dsDNA System (Promega, Madison, WI), and copy numbers were calculated according to the following formula: copy number $(\mathrm{g} / \mathrm{mole}-$ cule $)=$ (base pairs size of double-stranded plasmid containing the insert $) \times(330$ Daltons $\times 2$ nucleotides/base pairs $\div$ (Avogadro number $6.023 \times 10^{23}$ molecules $/ \mathrm{mole}$ ) . Standard curves of plasmid DNA containing the coding regions of HYBID and TMEM2 were generated with threshold cycle $\left(\mathrm{C}_{\mathrm{T}}\right)$ values obtained from quantitative realtime PCR of various copy numbers of the plasmids. The copy numbers of HYBID and TMEM2 molecules present in the synovial tissue samples were calculated by relating the PCR signal $\left(\mathrm{C}_{\mathrm{T}}\right.$ value $)$ of each synovial tissue sample to the standard curves.

\section{Immunohistochemistry}

Paraffin sections of OA synovial tissues were autoclaved at $121^{\circ} \mathrm{C}$ for 10 minutes in Target Retrieval Solution (DAKO Cytomation, Tokyo, Japan) for antigen retrieval, and nonspecific reactions were blocked with BLOCK ACE (DS Pharma Biomedical, Osaka, Japan). The sections were also treated with $3 \% \mathrm{H}_{2} \mathrm{O}_{2}$ to block peroxidase reactions. They were then immunostained with rabbit anti-HYBID (KIAA1199) antibody (SAB2105467; Sigma-Aldrich, St. Louis, MO), rabbit anti-IL-6 antibody (ab6672; Abcam, Cambridge, UK) or nonimmune control IgG (X0936; DAKO Cytomation), followed by incubation with biotinylated antibody against rabbit IgG according to the $\mathrm{ABC}$ method (Vector Laboratories, Burlingame, CA). Color was developed with 3-amino-9-ethylcarbazole chromogen (Vector Laboratories), and sections were counterstained with hematoxylin. Specificity of anti-HYBID (KIAA1199) antibody (SAB2105467; Sigma-Aldrich) was confirmed by the absorption test by incubating the antibody with the peptide antigen (KIAA1199 Blocking Peptide, 33R-7080; Fitzgerald Industries International, Acton, MA) prior to immunohistochemistry (data not shown).

\section{Immunofluorescence Microscopy}

Paraffin sections of OA synovial tissues were subjected to antigen retrieval with Target Retrieval Solution (DAKO
Cytomation), and nonspecific reactions and autofluorescence were blocked with BLOCK ACE (DS Pharma Biomedical). They were double-immunostained with mouse anti-CD68 antibody (clone PG-M1, M0876; DAKO Cytomation) and rabbit anti-HYBID (KIAA1199) antibody (SAB2105467; Sigma-Aldrich) or rabbit anti-IL-6 antibody (ab6672; Abcam, Cambridge, UK), followed by incubation with anti-mouse IgG antibody conjugated to Alexa Fluor 488 or anti-rabbit IgG antibody conjugated to Alexa Fluor 546 (Life Technologies, Carlsbad, CA). Similarly, double-immunofluorescence staining was performed with rabbit anti-HYBID (KIAA1199) antibody (SAB2105467; Sigma-Aldrich) and mouse anti-fibroblast-specific protein 1 (S100A4) antibody (ab218511; Abcam), followed by incubation with anti-rabbit IgG antibody conjugated to Alexa Fluor 546 or anti-mouse IgG antibody conjugated to Alexa Fluor 488 (Life Technologies). Nuclei were stained with Hoechst 33342 (Thermo Fisher Scientific, Tokyo, Japan), and images were obtained with a confocal microscope TCSSP5 (Leica, Wetzlar, Germany).

\section{Measurement of HA and HYBID Concentrations in OA Synovial Fluids}

HA in synovial fluid from OA patients was determined using QnE Hyaluronic Acid enzyme-linked immunosorbent assay (ELISA) (Biotech Trading Partners, Encinitas, CA) according to the manufacture's protocol. The assay detected HA molecular weight forms as small as 20 to 30 $\mathrm{kDa}$. The molecular weight of HA in OA synovial fluid was determined by size-exclusion gel filtration using Shodex OHpak SB-807 columns (Showa Denko, Tokyo, Japan). Fractions $(0.5 \mathrm{~mL})$ were collected, and the HA content was determined as described previously. ${ }^{17}$ The column was calibrated with HA species: sodium HA H2 $(2500 \mathrm{kDa})$, M2 (1000 kDa), and L2 (150 kDa), all of which were purchased from PG Research (Tokyo, Japan). The HYBID protein concentrations in OA synovial fluids were evaluated by densitometric analysis of immunoblotting data according to a standard curve determined using recombinant HYBID. ${ }^{17}$

\section{Cultures of OA Synovial Fibroblasts}

Synovial fibroblasts were isolated from human OA synovium by enzymatic dissociation and cultured in Dulbecco's modified Eagle's medium (Sigma-Aldrich) supplemented with $10 \%$ fetal bovine serum according to previously published methods. ${ }^{24,25}$ They were used for experiments at passages 1 to 4 (P1 to P4).

\section{Stimulation of OA Synovial Fibroblasts with Factors}

Serum-starved OA synovial fibroblasts at P3 were treated with histamine (Wako, Osaka, Japan), TGF- $\beta 1$ (R\&D Systems, Minneapolis, MN), IL-6 (R\&D Systems) plus soluble 
IL-6 receptor (sIL-6R) (R\&D Systems), IL-1 $\alpha$ (R\&D Systems), IL-8 (R\&D Systems), TNF- $\alpha$ (R\&D Systems), insulin-like growth factor-1 (IGF-1) (Sigma-Aldrich), vascular endothelial growth factor ${ }_{165}\left(\mathrm{VEGF}_{165}\right)$ (R\&D Systems), basic fibroblast growth factor (bFGF) (SigmaAldrich), prostaglandin E2 (PGE2) (Sigma-Aldrich), tumor necrosis factor- $\beta$ (TNF- $\beta$ ) (R\&D Systems), and C-C motif chemokine ligand 5 (CCL5) (R\&D Systems) or vehicle alone in Dulbecco's modified Eagle's medium containing $1 \%$ fetal bovine serum for 24 hours. The expression levels of $H Y B I D$ and TMEM2 were normalized to glyceraldehyde3-phosphate dehydrogenase (GAPDH) and determined by a SYBR Green real-time PCR assay (Invitrogen, Carlsbad, CA) according to the $\Delta \Delta C_{\mathrm{T}}$ method. ${ }^{26}$ Nucleotide sequences for the primers were as follows: for $H Y B I D$ 5'-AGGGAAGCAGGTCAGAGTGA-3' (forward) and 5'TCTCGGCTACAGACCCAGAG-3' (reverse); for TMEM2 $5^{\prime}$-ACTTGGTGGCTGGCATGTTC-3' (forward) and $5^{\prime}$ CATGAGCTGGGCCTGAGTTG- $3^{\prime}$ (reverse); and for GAPDH 5'-GCACCGTCAAGGCTGAGAAC-3' (forward) and $5^{\prime}$-TGGTGAAGACGCCAGTGGA-3' (reverse). The expression of HYAL1, HYAL2, HAS1, HAS2, and HAS3 in IL-6-treated OA synovial fibroblasts was also examined according to the method described above using the primers as follows: for HYAL1 5'-CCCAAGGTTGCACAGCAAGA-3' (forward) and 5'-ACTCAGTAGGAGTGCAAGGGCTGTA-3' (reverse); for HYAL2 5'-ACCAT GCACTCCCAGTCTACGTC-3' (forward) and $5^{\prime}$-TCGCC AATGGTAGAGATGAGGTC-3' (reverse); for HAS1 $5^{\prime}$ ATCCTGCATCAGCGGTCCTC- $3^{\prime}$ (forward) and $5^{\prime}$-CTG GTTGTACCAGGCCTCAAGAA-3'(reverse); for HAS2 5' GTAGGCATCCAGCACTGGACAA-3' (forward) and $5^{\prime}$ CCAGTAAATTCAGGCCACAGAACA-3' (reverse); and for HAS3 5'-TTGCAATCCAGGCTGTTCTCA-3' (forward) and 5'-GCTGTCCACCTTAGTGCTGGTTC$3^{\prime}$ (reverse). In addition, OA synovial fibroblasts (P3) treated with IL-6 $(0,10,50$, or $100 \mathrm{ng} / \mathrm{mL})$ in the presence of sIL6R $(100 \mathrm{ng} / \mathrm{mL})$ for 48 hours were subjected to immunoblotting with anti-HYBID antibody (Proteintech, Rosemont, IL) and anti-GAPDH antibody (as a loading control) (ab125247; Abcam).

\section{Effects of OA Synovial Fibroblasts with Tocilizumab}

Serum-starved OA synovial fibroblasts at P3 were treated with humanized anti-IL-6R antibody (tocilizumab; $25 \mu \mathrm{g} /$ $\mathrm{mL}$ ) (Actemra; Chugai Pharmaceutical Co., Tokyo, Japan) or nonimmune human IgG (25 $\mu \mathrm{g} / \mathrm{mL}$; R\&D Systems) in Dulbecco's modified Eagle's medium containing 1\% fetal bovine serum for 1 hour prior to stimulation with IL-6 ( 0 or $100 \mathrm{ng} / \mathrm{mL})$ and sIL-6R (100 ng/mL) for 48 hours, and then subjected to immunoblotting with anti-HYBID antibody (Proteintech). The effect of tocilizumab on HYBID mRNA and protein expression in serum-starved OA synovial fibroblasts at P1 was also tested by SYBR Green real-time PCR and immunoblotting analyses of the cells treated with nonimmune human $\operatorname{IgG}(25 \mu \mathrm{g} / \mathrm{mL})$ or tocilizumab $(1,5$, or $25 \mu \mathrm{g} / \mathrm{mL}$ ) for 24 hours and 48 hours, respectively.

\section{RNA Interference for HYBID}

A knockdown experiment was performed using two different siRNAs designed to target HYBID and nonsilencing control RNAs, both of which were purchased from Thermo Fisher Scientific (Waltham, MA). OA synovial fibroblasts were transfected with these siRNAs using Lipofectamine RNAiMAX Transfection Reagent (Thermo Fisher Scientific), and used for the experiment at 48 hours after transfection. Knockdown of the HYBID expression was confirmed by immunoblotting with antiHYBID antibody (Proteintech) and anti-GAPDH antibody (Abcam).

\section{Determination of HA-Degrading Activity, and Concentration and Molecular Size Distribution of HA}

Cellular HA-degrading activity was examined by culturing siRNA-transfected or IL-6-treated OA synovial fibroblasts in medium containing fluoresceinamine-labeled HA H1 (FAHA H1; $10 \mu \mathrm{g} / \mathrm{mL}$ ) for 48 hours and applying the harvested medium to a Sepharose CL-2B column $(1 \times 60 \mathrm{~cm}$; GE Healthcare, Tokyo, Japan) equilibrated with $0.5 \mathrm{~mol} / \mathrm{L} \mathrm{NaCl}$ in distilled water. ${ }^{21}$ Calibration was performed using the FAHA species including $\mathrm{H} 1$ (1800 kDa; average molecular size), M1 (1000 kDa), L1 (200 kDa), and S1 (50 kDa). ${ }^{21}$ Concentrations of $\mathrm{HA}$ in the medium from OA synovial fibroblasts treated with IL- $6(0,10,50$, and $100 \mathrm{ng} / \mathrm{mL})$ in the presence of sIL-6R $(100 \mathrm{ng} / \mathrm{mL})$ for 48 hours were determined using a QnE HA ELISA (Biotech Trading Partners). The molecular size distribution of HA was determined by applying medium harvested from IL-6 $(100 \mathrm{ng} / \mathrm{mL})$ and sIL$6 \mathrm{R}(100 \mathrm{ng} / \mathrm{mL})$-treated or untreated synovial fibroblasts to the Sepharose CL-2B column and measuring HA concentrations of each fraction by HA ELISA.

\section{Measurement of IL-6 in Culture Medium of OA Synovial Cells and Synovial Tissue Homogenates}

Concentrations of IL- 6 in the conditioned medium of the cells isolated from OA synovium without passage (P0) were measured using an ELISA kit (R\&D Systems) according to the manufacturer's protocols. The culture medium was prepared by culturing cells $\left(4 \times 10^{5}\right.$ cells/6$\mathrm{cm}$ dish) in $4 \mathrm{~mL}$ of Dulbecco's modified Eagle's medium containing $1 \%$ fetal bovine serum for 24 hours. Similarly, OA synovial tissues were homogenized in phosphate-buffered saline containing IGEPAL (CA-630; Sigma-Aldrich), and then IL-6 levels in the homogenate supernatants were determined by ELISA kit after determination of the protein concentrations using Protein Quantification Kit-Wide Range (DOJINDO, Kumamoto, Japan). 


\section{Statistical Analysis}

All data were analyzed using IBM SPSS Statistics software version 21.0 (IBM, Armonk, NY) and expressed as means \pm SD. For comparisons of the HYBID and TMEM2 expression levels between normal and OA synovial samples, the $U$-test was used. Comparisons involving more than 3 groups in the experiments using OA synovial fibroblasts were performed by the 1-way analysis of variance, followed by the Bonferroni test. Statistical significance was determined by $t$-test. Correlations were examined by Pearson test. $P<0.05$ was considered significant.

\section{Results}

Expression and Tissue Localization of HYBID in OA Synovium

This study measured the mRNA expression levels of HYBID and TMEM2, and found that HYBID is
A

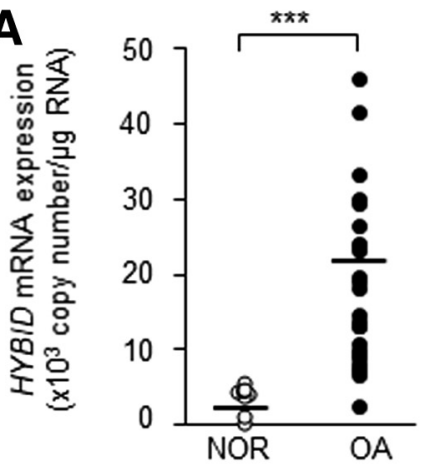

C

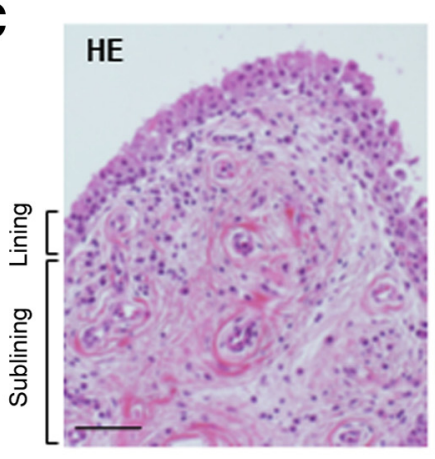

D

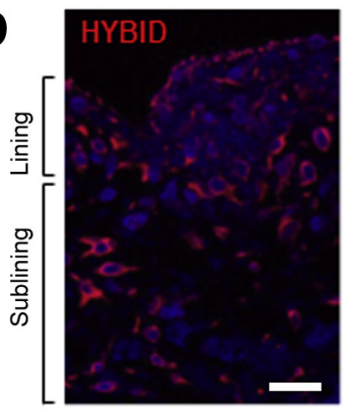

E

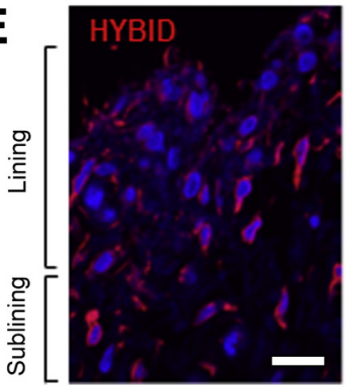

B

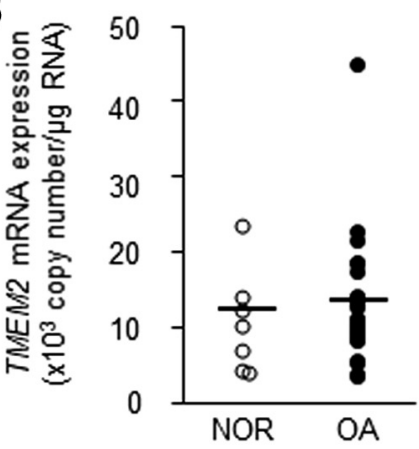

Figure 1 Expression of hyaluronan (HA)binding protein involved in HA depolymerization (HYBID) and transmembrane protein 2 (TMEM2), and tissue localization of HYBID in osteoarthritic (OA) synovium. A and B: Copy numbers of HYBID and TMEM2 transcripts in control normal (NOR) and $O A$ synovial samples. The copy numbers were determined by quantitative real-time PCR assay with standard curves generated from reference plasmids. Symbols represent individual subjects, and horizontal lines indicate means. C: Immunohistochemistry for HYBID in OA synovial tissue. Paraffin sections of $O A$ synovium were stained with hematoxylin and eosin (HE) or immunostained with anti-HYBID antibody (HYBID) or nonimmune IgG (NI). Boxed area is shown at higher magnification in the inset. D: Double immunofluorescence staining of HYBID and CD68. Paraffin sections of $O A$ synovial tissue were subjected to doubleimmunofluorescence staining for HYBID (red) and CD68 (green). E: Double-immunofluorescence staining of HYBID and fibroblast-specific protein 1 (FSP1). Paraffin sections of OA synovial tissue were subjected to double-immunofluorescence staining for HYBID (red) and FSP1 (green). $n=8$ NOR samples $(\mathbf{A}$ and $\mathbf{B}) ; n=27$ OA synovial samples (A and $\mathbf{B}) .{ }^{* * *} P<0.001$ (U-test). Scale bars: $50 \mu \mathrm{m}$ (C); $25 \mu \mathrm{m}$ (D and $\mathbf{E})$. 

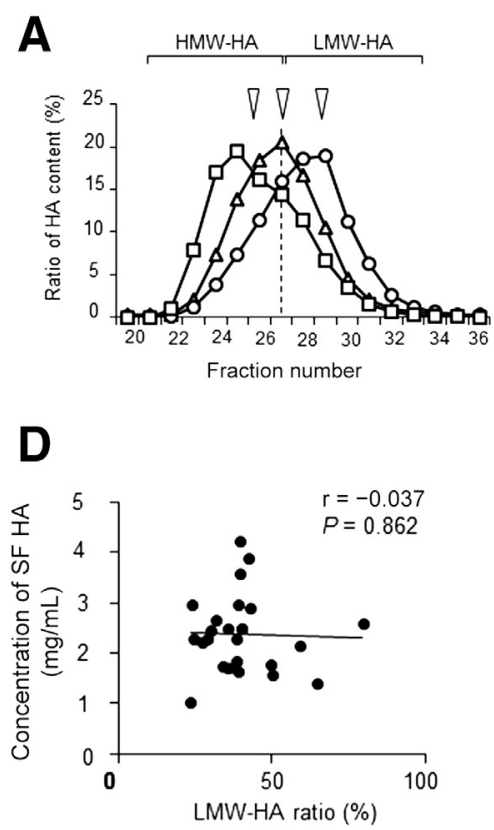

B
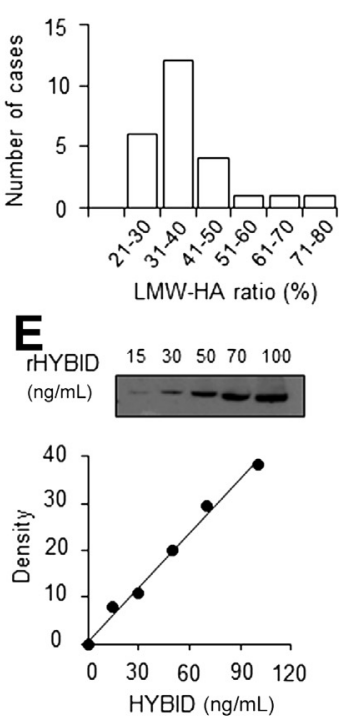

C

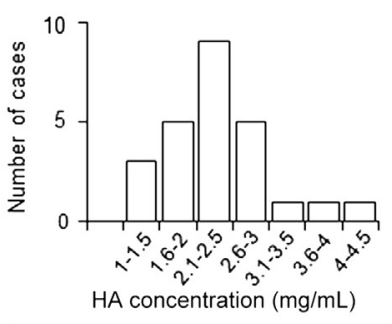

$\mathbf{F}$

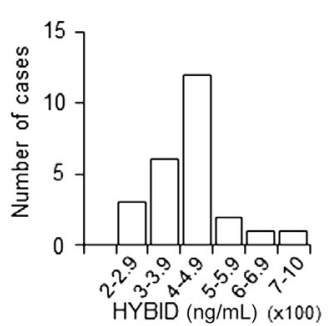

G

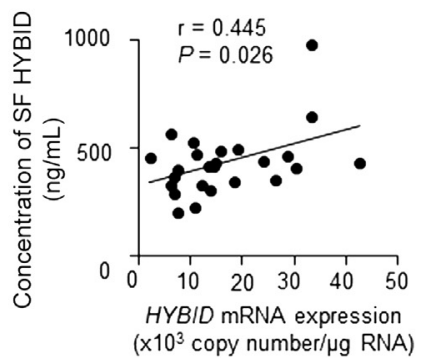

Figure 2 Measurement of molecular weight distribution and concentrations of hyaluronan (HA) and concentrations of hyaluronan (HA)-binding protein involved in HA depolymerization (HYBID) in osteoarthritic (OA) synovial fluids. A: Three representative cases of size distribution pattern of HA in OA synovial fluids. Molecular weights are determined by size-exclusion chromatography, and amount of HA in each fraction is shown as the ratio (\%) to total HA amount $(100 \%)$. High-molecular-weight (HMW)-HA and lower-molecular-weight (LMW)-HA were defined as HA species above and below $1000 \mathrm{kDa}$ (dashed line), respectively. Arrowheads indicate elution peaks of sodium HA species with $2500 \mathrm{kDa}, 1000 \mathrm{kDa}$, and $150 \mathrm{kDa}$ from left to right. B: Distribution of $0 \mathrm{~A}$ cases with different ratios (\%) of LMW-HA in synovial fluids. C: Distribution of OA cases with different HA concentrations in synovial fluids. D: Correlation between ratios of LMW-HA and HA concentrations in OA synovial fluids (SF). Pearson correlation coefficient analysis. Diagonal line shows the estimated regression line superimposed on the scatter diagram. E: The standard curve for HYBID protein. Different amounts of recombinant HYBID (rHYBID) were subjected to immunoblotting for HYBID, and densitometric analysis of the immunoreactive bands was performed. The line represents the trendline of the calibration curve. F: Distribution of OA cases with different HYBID concentrations in OA synovial fluids. HYBID concentrations in the synovial fluids were determined by immunoblotting according to the standard curve. G: Correlation between the HYBID mRNA expression levels (mRNA copy numbers per $\mu \mathrm{g}$ RNA) in 0A synovial tissue and the HYBID protein concentrations in OA synovial fluids (SF) by Pearson correlation coefficient analysis. Diagonal line shows the estimated regression line superimposed on the scatter diagram. $n=250 \mathrm{~A}$ cases (B, $\mathbf{C}$, and $\mathbf{F})$.

significantly 5.5 -fold higher in OA synovium $(20.2 \pm 12.1$ $\times 10^{3}$ copies per $\mu \mathrm{g}$ of total RNA) than in normal control synovium $\left(3.7 \pm 1.8 \times 10^{3}\right.$ copies per $\mu \mathrm{g}$ of total RNA) $(P<0.001)$ (Figure 1A). By contrast, the expression level of TMEM2 did not differ between OA $\left(13.0 \pm 8.1 \times 10^{3}\right.$ copies per $\mu \mathrm{g}$ of total RNA) and control synovium $\left(11.8 \pm 7.1 \times 10^{3}\right.$ copies per $\mu \mathrm{g}$ of total RNA) (Figure $1 \mathrm{~B}$ ). Immunohistochemistry showed that HYBID is localized mainly to synovial lining cells and also sublining cells and endothelial cells of capillaries in the $\mathrm{OA}$ synovium (Figure 1C), whereas only background staining was detected by immunostaining with nonimmune $\operatorname{IgG}$ (Figure 1C). Double immunofluorescence staining of HYBID and CD68 or that of HYBID and fibroblast-specific protein 1 in OA synovial tissue demonstrated that HYBID is positively immunostained in CD68-negative and fibroblast-specific protein 1 -positive synovial lining cells and sublining cells (Figure 1, D and E). Because synovial lining cells are composed of macrophage-like type A cells and fibroblastlike type $\mathrm{B}$ cells $^{27}$ and sublining cells contain fibroblasts and macrophages in OA synovium, ${ }^{28,29}$ the data suggest that HYBID could be expressed mainly by fibroblast-like type B cells and fibroblasts in the lining and sublining cell layers, respectively.

\section{Measurement of Molecular Weight Distribution of HA and HYBID Concentration in OA Synovial Fluids}

The molecular weight distribution of HA in OA synovial fluids was determined by size-exclusion chromatography. The peak of HA molecular weight and the distribution of HA species varied among the samples (Figure 2A). Because a previous study has demonstrated that the weight $\%$ of HA below $1000 \mathrm{kDa}$ is associated with progression of knee $\mathrm{OA}^{8}{ }^{8}$ the ratios (\%) of HA species below $1000 \mathrm{kDa}$ (ie, LMW-HA) to total HA, which is composed of LMW-HA below $1000 \mathrm{kDa}$ and HMW-HA over $1000 \mathrm{kDa}$, were calculated. The LMW-HA ratios ranged from $23 \%$ to $80 \%$ in the samples, and the median value was $38.6 \%$ (mean $\pm \mathrm{SD}, 39.7 \pm 13.1 \%$ ) (Figure 2B). HA concentrations in OA synovial fluids determined by ELISA ranged from $1.0 \mathrm{mg} / \mathrm{mL}$ to $4.2 \mathrm{mg} / \mathrm{mL}$, showing the median value of $2.3 \mathrm{mg} / \mathrm{mL}$ (mean $\pm \mathrm{SD}, 2.4 \pm 0.8 \mathrm{mg} / \mathrm{mL}$ ) (Figure 2C). There was no correlation between the LMW-HA ratios and 
the HA concentrations in OA synovial fluids (Figure 2D). To evaluate concentrations of HYBID in OA synovial fluids, the samples of synovial fluid were subjected to immunoblotting for HYBID, and band densities determined by densitometric analysis was compared with the standard curve obtained using recombinant HYBID (Figure 2E). The concentrations were distributed from $204 \mathrm{ng} / \mathrm{mL}$ to $982 \mathrm{ng} /$ $\mathrm{mL}$ with a median value of $420 \mathrm{ng} / \mathrm{mL}$ (mean $\pm \mathrm{SD}$, $432 \pm 152 \mathrm{ng} / \mathrm{mL}$ ) (Figure 2F). Importantly, a direct correlation was obtained between the concentrations of HYBID protein in OA synovial fluid and the HYBID mRNA expression levels (copy numbers per $\mu \mathrm{g}$ of total RNA) in OA synovium (Figure 2G).

\section{Correlation of HYBID and TMEM2 Expression with HA Depolymerization in OA Synovial Fluids}

The mRNA expression levels of HYBID (copy numbers per $\mu \mathrm{g}$ of total RNA) in OA synovial tissue directly correlated with the LMW-HA ratios in synovial fluids $(\mathrm{r}=0.511 ; P=0.009)$ (Figure 3A), although there was no positive correlation between the mRNA expression levels of HYBID and the HA concentrations in synovial fluids ( $\mathrm{r}=-0.386 ; P=0.057$ ) (Figure 3B). Similarly, the concentrations of HYBID protein in synovial fluids directly correlated with the LMW-HA ratios in synovial fluids ( $\mathrm{r}=0.764 ; P<0.001$ ) (Figure 3C), but not with the HA concentrations in synovial fluids $(\mathrm{r}=0.012$; $P=0.956$ ) (Figure 3D). Neither the mRNA nor protein expression levels of HYBID showed positive correlations with the serum concentrations of HA (Figure 3, E and F). In addition, the serum HA concentrations did not correlate with the HA concentrations or the LMW-HA ratios in synovial fluids (Figure 3, G and H). When correlations of the mRNA expression levels of TMEM2 (copy numbers per $\mu \mathrm{g}$ of total RNA) in OA synovial tissue with the LMW-HA ratios in synovial fluids, the HA concentrations in synovial fluids, or the serum concentrations of HA were examined, no positive correlations were obtained (Supplemental Figure S1).

\section{Effects of Factors on HYBID and TMEM2 Expression in OA Synovial Fibroblasts}

Because HYBID was originally discovered by microarray analysis of dermal fibroblasts as a gene that is up-regulated and down-regulated by histamine and TGF- $\beta 1$, respectively, ${ }^{17}$ this study first examined the expression by quantitative real-time PCR in OA synovial fibroblasts at P3 treated with these factors, and confirmed up-regulation by histamine and down-regulation by TGF- $\beta 1$ (Figure 4A). By treating OA synovial fibroblasts with 10 other factors including IL-6, IL-1 $\alpha$, IL-8, TNF- $\alpha$, VEGF, bFGF, PGE2, IGF-1, TNF- $\beta$, and CCL5, all of which are known to exist in joint tissues in arthritides such as $\mathrm{OA},{ }^{12,30,31}$ this investigation demonstrated that only IL-6 significantly promotes the HYBID mRNA expression (Figure 4A). Immunoblotting analysis confirmed the stimulative effect of IL-6 on HYBID protein expression (Figure 4B), and this stimulation was abrogated by treating them with anti-IL6R antibody (tocilizumab) (Figure 4C), indicating that the stimulative effect is due to IL-6. In addition, the basal expression levels of HYBID mRNA and protein in nontreated OA synovial fibroblasts at P1 were significantly reduced by treatment with tocilizumab to about $45 \%$ of the original levels (Figure 4, D and E). When production levels of IL- 6 by the cells (P0) directly isolated from OA synovial tissues were measured by ELISA, they produced IL-6 at a concentration of $262.2 \pm 164.3 \mathrm{ng} / \mathrm{mL}$ for 24 hours $(n=3)$.

This study also examined effects of these factors on the TMEM2 expression in OA synovial fibroblasts, and found that the expression is slightly up-regulated by TNF- $\beta$ and down-regulated by PGE2 and IGF-1 (Supplemental Figure S2). However, no changes in the expression of TMEM2, HYAL1, and HYAL2 was observed by treatment with IL-6 (Supplemental Figure S2). HA-degrading activity of OA synovial fibroblasts completely disappeared by knocking down the HYBID expression by siRNAs (Figure $5 \mathrm{~A}$ ), whereas the activity was up-regulated by treatment with IL-6 (Figure 5B). Under stimulation of OA synovial fibroblasts with IL-6, HA production tended to be slightly increased (Figure 5C), and the expression of $H A S 2$, but not HAS1 or $H A S 3$, was significantly enhanced by treatment with IL-6 (Figure 5D). When the molecular size distribution of newly produced HA was analyzed by the gel filtration chromatography, LMW-HA species appeared to be increased by IL-6-treated fibroblasts compared with those without treatment (Figure 5E).

\section{Expression and Tissue Localization of IL-6 in OA} Synovium, and Positive Correlation between the IL- 6 and HYBID Expression Levels

Immunohistochemistry showed that IL-6 is produced mainly by synovial lining cells and sublining cells, whereas nonimmune $\operatorname{IgG}$ showed only background staining (Figure 6A). Double immunofluorescence staining of IL-6 and CD68 indicated that CD68-positive cells (macrophage-like type A cells) and CD68-negative cells (fibroblast-like type B cells) in the synovial lining cell layer and CD68-positive macrophages and CD68-negative fibroblasts in the sublining cell layer are positively immunostained (Figure 6B), suggesting that IL-6 is produced by both cell types of macrophages and fibroblasts. The IL-6 production levels in OA synovial tissue by ELISA were first measured, and their production levels were compared with the HYBID mRNA expression levels. As shown in Figure 6C, the HYBID expression levels (copy numbers per $\mu \mathrm{g}$ of total RNA) directly correlated with IL-6 concentrations. 

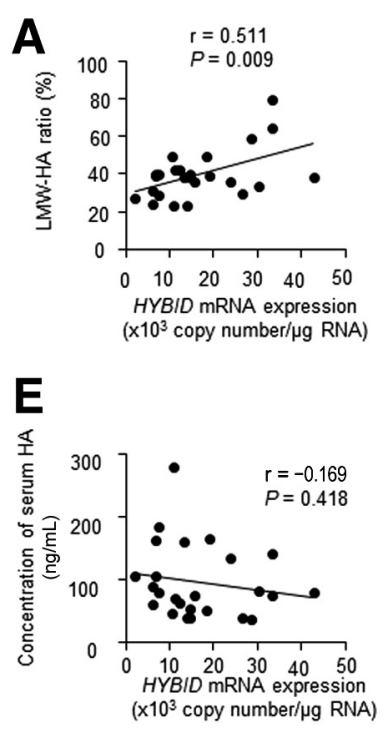

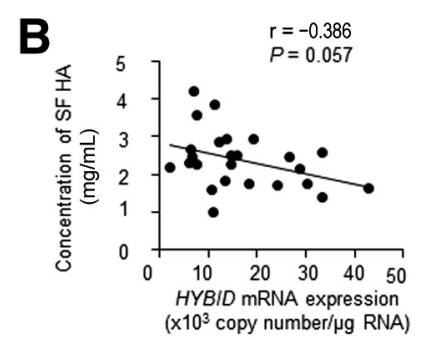

$\mathbf{F}$

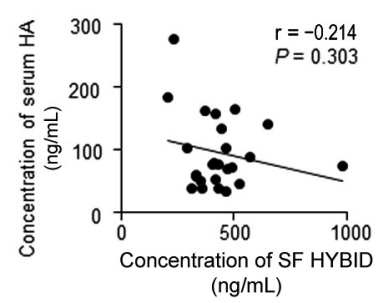

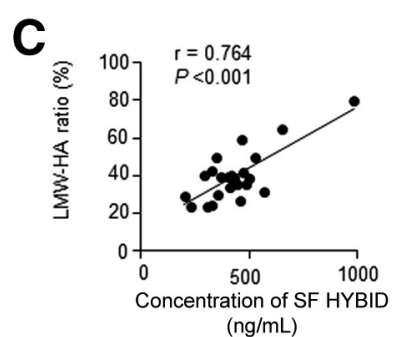
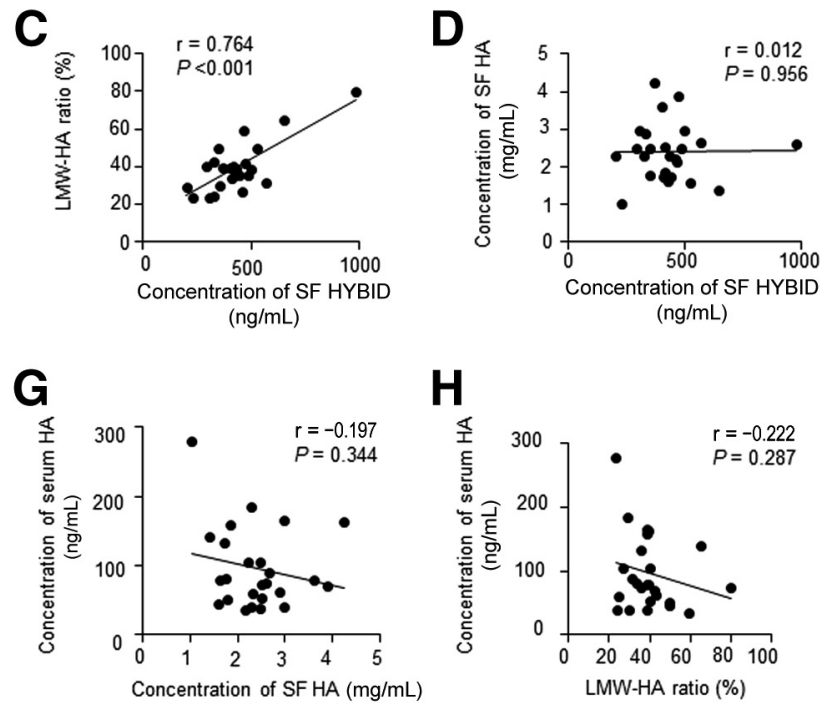

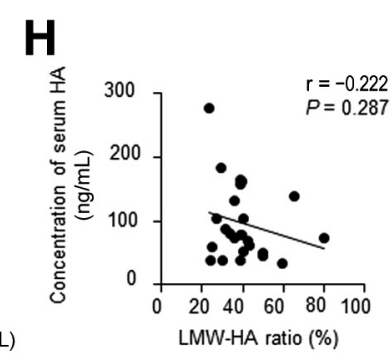

Figure 3 Correlations of hyaluronan (HA)-binding protein involved in HA depolymerization (HYBID) expression with hyaluronan (HA) depolymerization in osteoarthritic (OA) synovial fluids. A and B: Correlations of the HYBID mRNA expression levels (mRNA copy numbers per $\mu$ g RNA) in OA synovial tissue with lower molecular weight (LMW)-HA ratios or HA concentrations in synovial fluids (SF). C and D: Correlations of the concentration of HYBID protein with LMW-HA ratios or HA concentrations in OA SF. $\mathbf{E}$ and $\mathbf{F}$ : Correlations of the HYBID mRNA expression levels (mRNA copy numbers per $\mu \mathrm{g}$ RNA) in synovial tissue or HYBID protein expression in OA SF with the concentrations of serum HA. G: Correlation between the HA concentrations in SF and the concentrations of serum HA. H: Correlation between the LMW-HA ratios in OA SFs and the concentrations of serum HA. Pearson correlation coefficient analysis was used for all of the analyses. Diagonal lines show the estimated regression lines superimposed on the scatter diagrams. $r$, correlation coefficient. $n=25(\mathbf{A}-\mathbf{H})$.

\section{Discussion}

This study provides the first evidence that HYBID is overexpressed in OA synovium compared with control normal synovium, whereas the TMEM2 expression is constitutively expressed in normal and OA synovia. Although the expression of murine TMEM2 was reported higher than that of HYBID in most mouse normal tissues including the brain, eye, heart, lung, liver, gastrointestinal tract, kidney, bladder, articular cartilage, and synovium, ${ }^{32}$ only limited information was available for the expression and role of TMEM2 in human tissues under various pathophysiological conditions. The study data on the expression of HYBID and TMEM2 indicate the possibility that differently from mouse normal synovium, HYBID, but not TMEM2, may play a key role in HA degradation in OA.

Band et $\mathrm{al}^{8}$ have recently reported that in a 3-year followup study of OA patients, the risk of knee OA progression is associated with the preponderance of LMW-HA (ie, the weight $\%$ of HA below $1000 \mathrm{kDa}$ ), but not average HA molecular weight, in synovial fluid. This study did not provide information about the mechanism on HMW-HA degradation in OA synovial fluids, although it was speculated that LMW-HA may be generated by the action of reactive oxygen species, which are known to randomly digest HA. ${ }^{33}$ The present study demonstrated that the LMW-HA ratios in OA synovial fluid directly correlate with the expression levels of HYBID mRNA and protein in OA synovial tissue and synovial fluids, respectively. The double-immunofluorescence study on OA synovium has indicated that CD68-negative and fibroblast-specific protein 1-positive synovial lining and sublining cells express HYBID protein. It is previously shown that HYBIDmediated HA degradation in fibroblasts occurs through the clathrin-coated pit pathway without intracytoplasmic accumulation, releasing HA fragments into the extracellular milieu. ${ }^{17}$ Altogether, HYBID overexpressed by synovial fibroblast-like type B cells and sublining fibroblasts in OA synovial membrane seems to play a central role in degradation of HMW-HA and subsequent accumulation of LMW-HA in OA synovial fluid, although implication of reactive oxygen species in HA degradation is not completely excluded.

HYBID expression was stimulated by IL-6. Similar to skin fibroblasts, ${ }^{17}$ the HYBID expression was also promoted by histamine, but the up-regulation rate was higher by treatment with IL-6 than histamine. A recent study indicated that HYBID expression in OA chondrocytes is up-regulated by TNF- $\alpha,{ }^{34}$ but TNF- $\alpha$ exerted no influence in OA synovial fibroblasts. The different responses to these cytokines suggest that regulation of HYBID gene expression may be cell-type specific, although detailed mechanisms remain unclear. Because human anti-IL-6R antibody (tocilizumab) abrogated the IL-6-stimulated HYBID expression in OA synovial fibroblasts at $\mathrm{P} 3$ to the basal level and reduced the expression by about $45 \%$ of the original level in synovial fibroblasts at P1, HYBID expression in OA synovial fibroblasts can be ascribed, at least in part, to the IL-6/IL-6R signaling pathways. In contrast to HYBID, modulation of TMEM2 expression by these factors was minimal, showing only a slight increase by TNF- $\beta$ and a decrease by PGE2 or IGF-1. The data seem to be in accord with the constitutive 
A

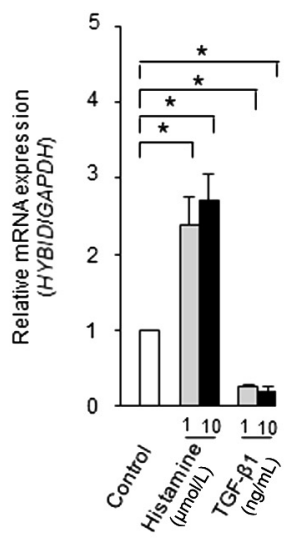

B

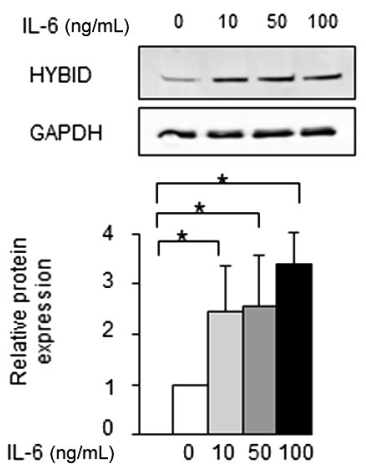

C
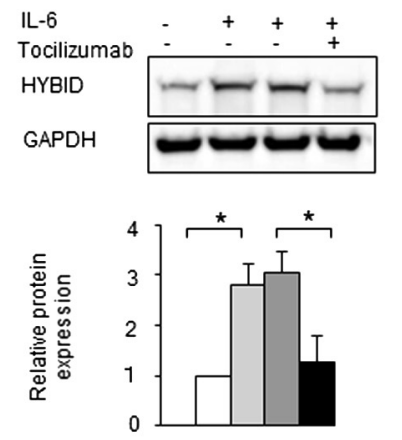

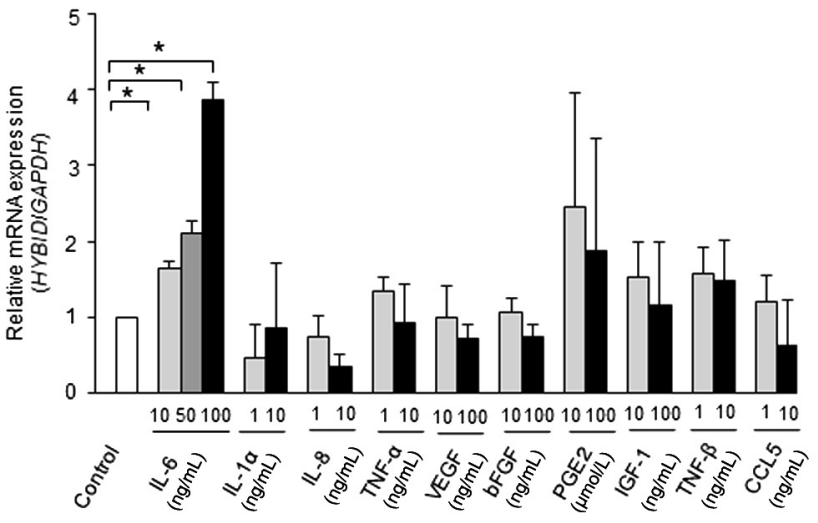

D

E

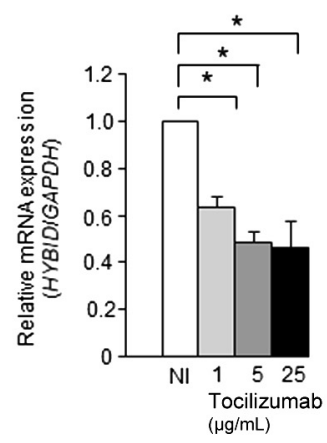

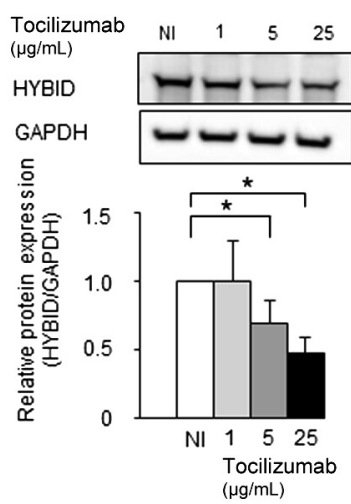

Figure 4 Promotion of the hyaluronan (HA)-binding protein involved in HA depolymerization (HYBID) expression by IL-6 in osteoarthritic (0A) synovial fibroblasts. A: Effects of histamine, transforming growth factor- $\beta 1$ (TGF- $\beta 1)$, IL- $6(+100 \mathrm{ng} / \mathrm{mL}$ sIL-6R), IL- $1 \alpha, \mathrm{IL}-8$, tumor necrosis factor- $\alpha$ (TNF- $\alpha$ ), vascular endothelial growth factor (VEGF), basic fibroblast growth factor (bFGF), prostaglandin E2 (PGE2), insulin-like growth factor-1 (IGF-1), tumor necrosis factor $\beta$ (TNF- $\beta$ ), and C-C motif chemokine ligand 5 (CCL5) on the HYBID mRNA expression in OA synovial fibroblasts. OA synovial fibroblasts (P3) were treated with these factors or vehicle alone for 24 hours, and the relative mRNA expression of $H Y B I D$ to $G A P D H$ was measured by quantitative real-time PCR using the $\triangle \triangle C_{T}$ method. The average HYBID:GAPDH ratio in control OA synovial fibroblasts treated with vehicle was set at 1 . B: Immunoblotting analysis of HYBID expression in $0 \mathrm{~A}$ synovial fibroblasts (P3) treated with IL-6. The cells were stimulated with IL-6 $(0,10,50$, and $100 \mathrm{ng} / \mathrm{mL})$ in the presence of sIL-6R (100 ng/mL) for $48 \mathrm{hours,}$ and cell lysates were subjected to immunoblotting with anti-HYBID antibody, followed by densitometric analysis. C: Effect of anti-IL-6R antibody (tocilizumab) on the IL-6-stimulated HYBID protein expression in OA synovial fibroblasts (P3). The cells were stimulated with IL-6 ( 0 or $100 \mathrm{ng} / \mathrm{mL})$ in the presence of sIL-6R $(100 \mathrm{ng} / \mathrm{mL})$ with nonimmune IgG $(25 \mu \mathrm{g} / \mathrm{mL})$ or tocilizumab $(25 \mu \mathrm{g} / \mathrm{mL})$ for 48 hours, and cell lysates were subjected to immunoblotting with anti-HYBID antibody, followed by densitometric analysis. D: Effect of anti-IL-6R antibody (tocilizumab) on the HYBID mRNA expression in OA synovial fibroblasts (P1). The cells were treated with nonimmune human IgG (NI; $25 \mu \mathrm{g} / \mathrm{mL})$ or tocilizumab $(1,5$ and $25 \mu \mathrm{g} / \mathrm{mL})$ for 24 hours, and the HYBID expression was determined by quantitative real-time PCR using the $\Delta \Delta C_{\mathrm{T}}$ method. E: Effect of anti-IL-6R antibody (tocilizumab) on the HYBID protein expression in 0A synovial fibroblasts (P1). The cells were treated as described above for 48 hours and then subjected to immunoblotting with anti-HYBID antibody, followed by densitometric analysis. Data are expressed as means \pm SD. $n=25$ (experiments). ${ }^{\star} P<0.05$.

expression pattern of TMEM2 in normal and OA synovial tissues. In addition, no changes in the HYAL1 and HYAL2 expression in response to IL-6 suggest negligible effect of these enzymes on the IL-6-stimulated HA-degrading activity in $\mathrm{OA}$ synovial fibroblasts.

IL-6 is overproduced in OA synovium and increased in serum samples from OA patients. ${ }^{35-37}$ IL-6 levels in OA synovial fluids $(396 \pm 508 \mathrm{pg} / \mathrm{mL})$ are reported to be approximately 6.2 -fold higher than that in healthy subjects $(64 \pm 120 \mathrm{pg} / \mathrm{mL}){ }^{38}$ Although information about production levels at local tissues such as OA synovium was limited, data in the present study showed that primary
OA synovial cells ( $\mathrm{P} 0)$, which were directly isolated from OA synovial tissue containing heterogeneous cells including fibroblasts and inflammatory cells, produce a high level of IL-6 $(262.2 \pm 164.3 \mathrm{ng} / \mathrm{mL})$ in the culture medium within 24 hours. Similar levels of IL-6 production (more than $100 \mathrm{ng} / \mathrm{mL}$ ) are also reported in conditioned medium of OA synovial tissue organ culture. ${ }^{39}$ Therefore, it seems likely that $100 \mathrm{ng} / \mathrm{mL}$ IL-6, which was utilized for stimulation of OA synovial fibroblasts in the present study and also commonly used for stimulation of cultured cells, ${ }^{40-42}$ is an appropriate concentration to recapitulate the stimulation of HYBID expression in 


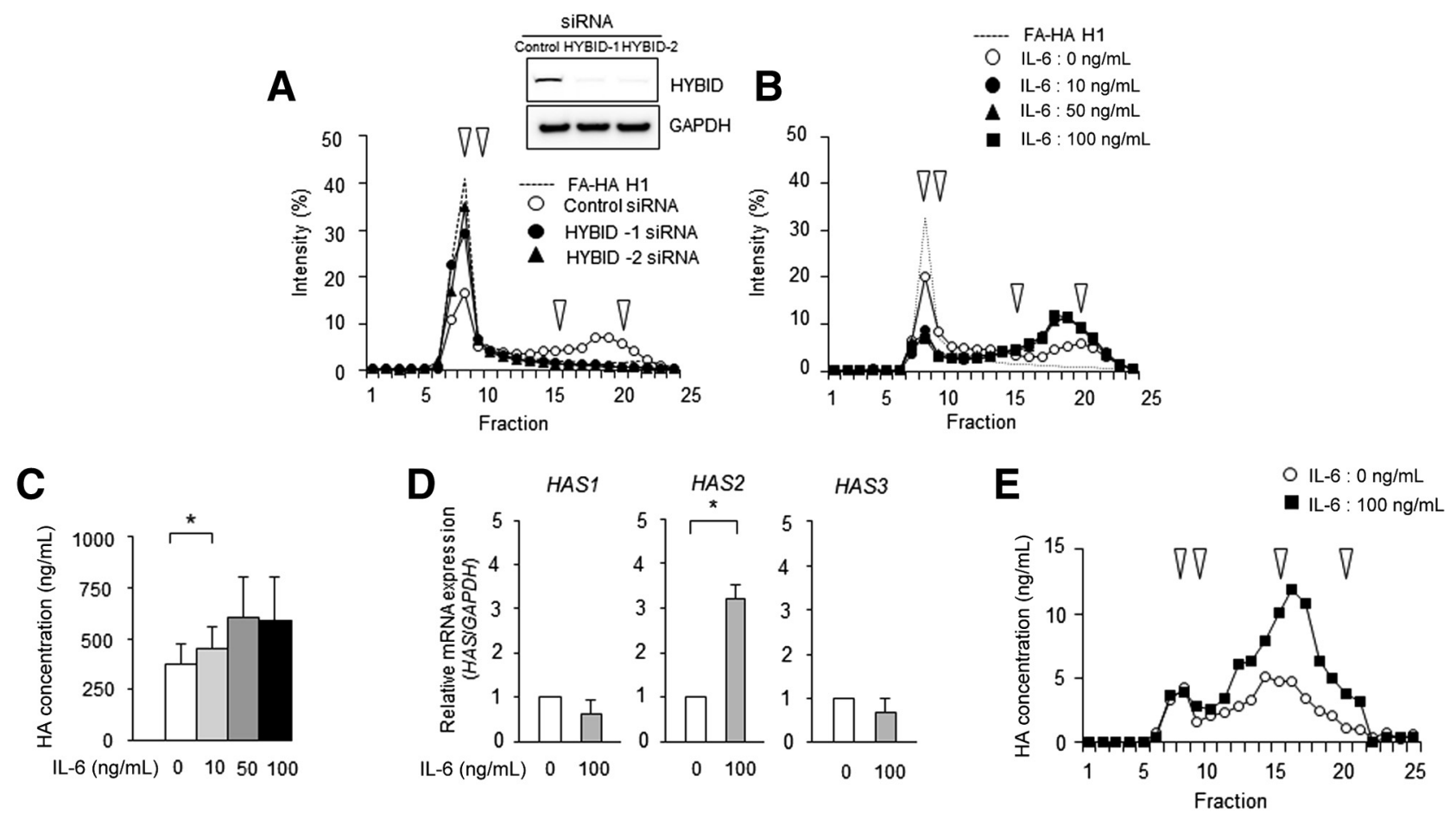

Figure 5 Hyaluronan (HA)-binding protein involved in HA depolymerization (HYBID)-mediated HA-degrading activity of osteoarthritic (OA) synovial fibroblasts and effects of IL-6 on HA-degrading activity and synthesized HA species. A: Abrogation of HA-degrading activity by knocking down HYBID expression with two different siRNAs. OA synovial fibroblasts transfected with siRNA for HYBID or nonsilencing RNA (Control) were cultured with FA-HA H1 for 48 hours, and HA-degrading activity was determined by gel filtration chromatography. Immunoblot analysis for HYBID and glyceraldehyde-3-phosphate dehydrogenase (GAPDH) (a loading control) is shown. B: HA-degrading activity in OA synovial fibroblasts treated with IL-6. OA synovial fibroblasts were stimulated with IL-6 $(0,10,50$, and $100 \mathrm{ng} / \mathrm{mL})$ and sIL-6R $(100 \mathrm{ng} / \mathrm{mL})$, and cultured with FA-HA H1 for 48 hours. HA-degrading activity was determined by gel filtration chromatography. Enhanced HA-degrading activity appears to be saturated by treatment with $10 \mathrm{ng} / \mathrm{mL} \mathrm{IL-6}$ in this assay. C: HA content in the culture medium of OA synovial fibroblasts stimulated with IL-6. Cells were cultured in the absence or presence of IL-6 for 48 hours, and concentrations of HA produced in the medium were quantified by enzyme-linked immunosorbent assay. D: Quantitative real-time PCR analysis of the HA synthase HAS1, HAS2, and HAS3 gene expression in $0 A$ synovial fibroblasts treated without or with $100 \mathrm{ng} / \mathrm{mL}$ IL-6 and sIL-6R. Relative expression levels were determined by normalizing to the expression level of GAPDH transcripts using the $\Delta \Delta C_{T}$ method. E: The size distribution of newly synthesized HA in OA synovial fibroblasts. Cells were cultured in the absence or presence of $100 \mathrm{ng} / \mathrm{mL}$ IL- 6 and SIL-6R for 48 hours. The conditioned medium was subjected to gel filtration chromatography, and HA concentrations in each fraction were determined by enzyme-linked immunosorbent assay. Arrowheads indicate elution peaks of FA-HA with $1800 \mathrm{kDa}, 1000$ $\mathrm{kDa}, 200 \mathrm{kDa}$, and $50 \mathrm{kDa}$ from left to right. Data are expressed as means $\pm \mathrm{SD} . n=3$ (C and D). ${ }^{\star} P<0.05$.

synovial fibroblasts under pathological conditions including OA synovitis.

IL-6 is known to be secreted by many cell types including monocytes/macrophages, endothelial cells, smooth muscle cells and fibroblasts such as synovial fibroblasts. ${ }^{38,39,43,44}$ Actually, the current immunohistochemical study showed that IL-6 is localized to CD68-positive macrophage-like type A cells and CD68-negative fibroblast-like type B cells in synovial lining cell layer, and also to CD68-positive macrophages and CD68-negative fibroblasts in sublining cell layer. These data suggest the IL-6 production by both macrophages and fibroblasts in the lining and sublining cell layers of OA synovium. The expression levels of IL-6 in OA synovial tissue homogenates directly correlated with the HYBID expression levels. Therefore, these studies support the hypothesis that IL-6 produced by the synovial cells stimulates synovial fibroblast-like type B cells in the lining cell layer and sublining fibroblasts to overexpress HYBID through an autocrine and/or paracrine pathway, and HYBID depolymerizes HMW-HA, leading to accumulation of LMW-HA species in OA synovial fluid (Figure 6D).

There are several limitations in this study. One is that the OA and normal control synovial samples were not agematched. Because no information is available on the effect of aging on the expression of HYBID and TMEM2 in human cells such as synovial fibroblasts, this study cannot exclude the possible involvement of aging in HYBID upregulation in OA synovium. However, the expression profiles of HYBID and TMEM2 in synovial tissues and OA synovial fibroblasts treated with various factors suggest that the expression is differently controlled, showing the cytokine-inducible and constitutive expression of HYBID and TMEM2, respectively. The current study has shown that the concentrations of HYBID protein in OA synovial fluid directly correlate with the LMW-HA ratios in the synovial fluid, and considered that this finding suggests the possible involvement of HYBID in HA degradation. However, because the HA-degrading activity 

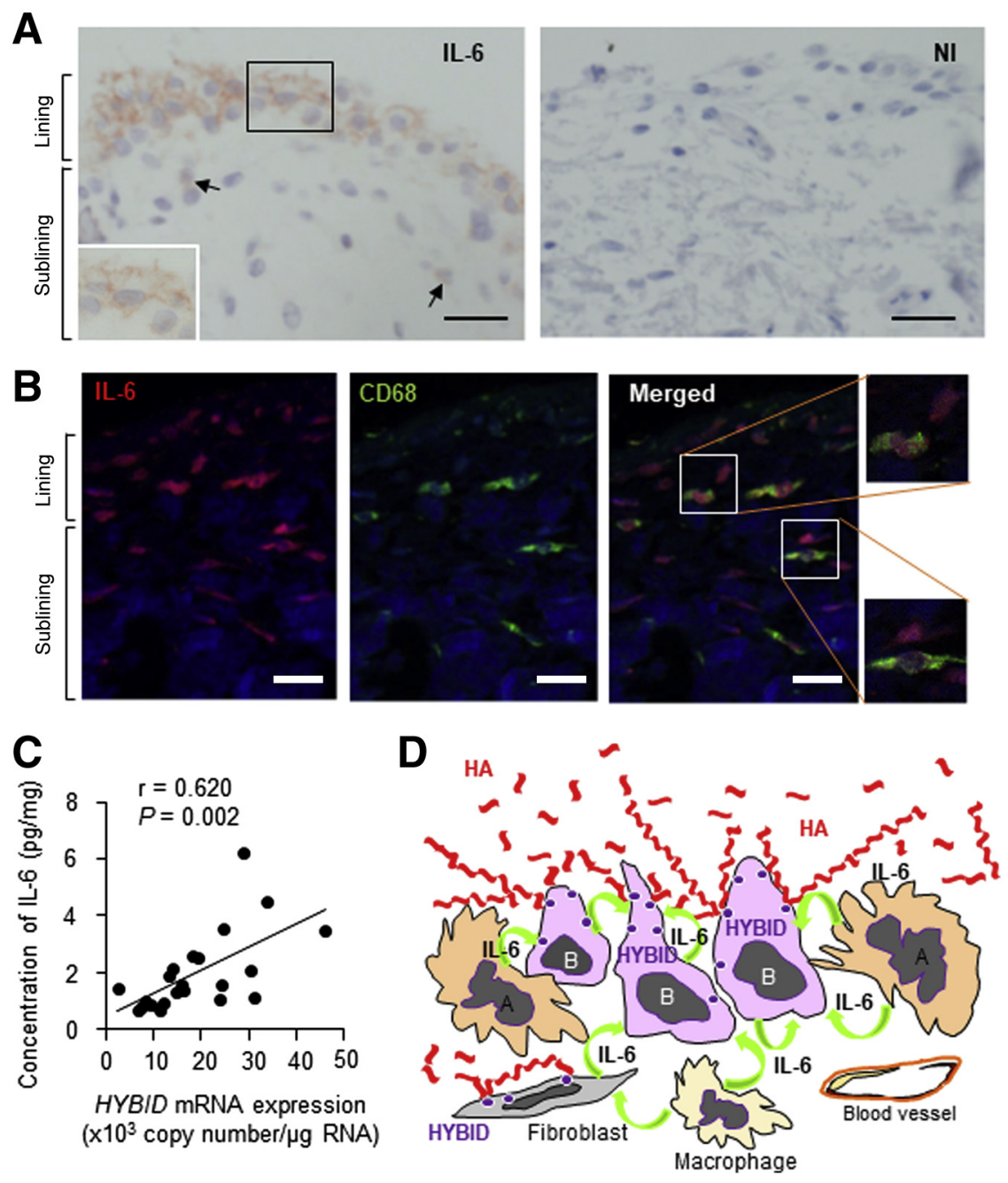

Figure 6 Tissue localization of IL- 6 and correlation between the IL- 6 concentrations and the hyaluronan (HA)-binding protein involved in HA depolymerization (HYBID) expression in osteoarthritic (OA) synovial tissue. A: Immunohistochemistry of IL-6 in OA synovial tissue. Paraffin sections of $O A$ synovium was immunostained with anti-IL-6 antibody (IL-6) or nonimmune IgG (NI). Boxed area is shown at higher magnification in the inset. Arrows denote IL-6-positive cells in sublining cell layer. B: Double immunofluorescence staining of IL- 6 and HYBID. Paraffin sections of OA synovial tissue were subjected to doubleimmunofluorescence staining for IL-6 (red) and CD68 (green). C: Correlation between the IL-6 concentrations and the HYBID mRNA expression (mRNA copy numbers per $\mu \mathrm{g}$ RNA) in OA synovial tissue. Diagonal line shows the estimated regression line superimposed on the scatter diagram. D: Schematic diagram showing the hypothesis on the HYBID expression and the HYBIDmediated HA degradation by an autocrine/paracrine pathway of IL- 6 and HYBID in OA synovial tissue. $n=22(\mathbf{C})$. Scale bars $=25 \mu \mathrm{m}(\mathbf{A}$ and $\mathbf{B})$. of secreted HYBID has not been demonstrated, ${ }^{17}$ the function of HYBID in synovial fluid remains unclear. Nonetheless, the data showing the direct correlation between the HYBID mRNA expression in OA synovial tissue and the HYBID protein expression in the synovial fluid suggest that HYBID protein originates from OA synovial fibroblasts, and reflects the overexpression of HYBID by OA synovial fibroblasts. Another question is what factors other than IL-6 contribute to the up-regulation of the HYBID expression in OA synovial fibroblasts. The present study has shown that IL-6 is a strong stimulator for HYBID expression in OA synovial fibroblasts, but complete suppression of HYBID expression was not obtained by treating them with anti-IL-6R antibody. In addition, this study did not provide the in vivo data directly showing that IL-6 exerts an effect on the HYBID expression in OA synovium. As expected from the authors' previous study with skin fibroblasts, ${ }^{17}$ histamine also stimulated HYBID expression. Detailed further studies are needed to clarify the regulation mechanisms of HYBID expression in OA synovial tissue.
In summary, this investigation has demonstrated that HYBID overexpressed by synovial fibroblast-like type B cells and sublining fibroblasts in OA synovium plays a key role in HA degradation in OA synovial fluid. Accumulated lines of evidence have established the notion that HMW-HA plays an essential role in maintaining the viscosity and functioning as shock-absorber in synovial fluid. ${ }^{1,2}$ In addition, HMW-HA is known to have anti-inflammatory and antiangiogenic activity, whereas LMW-HA is proinflammatory and proangiogenic. ${ }^{6,7}$ Therefore, maintaining HMW-HA in OA synovial fluid seems to be important, not only to avoid persistent damage of articular cartilage by mechanical stress enhanced due to HA degradation, but also to slow down the OA progression by attenuating synovitis. Because this study has provided the data that IL-6 is a stimulator of HYBID expression in OA synovium, IL-6 can be a molecular target in OA patients. Thus, therapeutic strategies may include application of IL-6 or IL-6R blockade and development of inhibitors to HYBID activity and/or molecules to selectively suppress the expression. However, deliberate and detailed analyses on the 
characteristics and role of HYBID in pathophysiological conditions are necessary.

\section{Acknowledgments}

We thank Dr. Hidetaka Eguchi for advice regarding absolute quantification of mRNA copy numbers for HYBID and TMEM2, which was performed at the Intractable Disease Research Center, Juntendo University Graduate School of Medicine; Dr. Kiran Chada, (Rutgers-Robert Wood Johnson Medical School) for reviewing this manuscript; and Chugai Pharmaceutical Co., Ltd., for human anti-IL-6R antibody [tocilizumab (Actemra)].

\section{Supplemental Data}

Supplemental material for this article can be found at http://doi.org/10.1016/j.ajpath.2020.01.003.

\section{References}

1. Uebelhart D, Williams JM: Effects of hyaluronic acid on cartilage degradation. Curr Opin Rheumatol 1999, 11:427-435

2. Tamer TM: Hyaluronan and synovial joint: function, distribution and healing. Interdiscip Toxicol 2013, 6:111-125

3. Vuorio E, Einola S, Hakkarainen S, Penttinen R: Synthesis of underpolymerized hyaluronic acid by fibroblasts cultured from rheumatoid and non-rheumatoid synovitis. Rheumatol Int 1982, 2: 97-102

4. Noble PW: Hyaluronan and its catabolic products in tissue injury and repair. Matrix Biol 2002, 21:25-29

5. Stern R, Asari AA, Sugahara KN: Hyaluronan fragments: an information-rich system. Eur J Cell Biol 2006, 85:699-715

6. West DC, Hampson IN, Arnold F, Kumar S: Angiogenesis induced by degradation products of hyaluronic acid. Science 1985, 228: $1324-1326$

7. Rooney P, Kumar S, Ponting J, Wang M: The role of hyaluronan in tumour neovascularization (review). Int J Cancer 1995, 60:632-636

8. Band PA, Heeter J, Wisniewski H-G, Liublinska V, Pattanayak CW, Karia RJ, Stabler T, Balazs EA, Kraus VB: Hyaluronan molecular weight distribution is associated with the risk of knee osteoarthritis progression. Osteoarthritis Cartilage 2015, 23:70-76

9. Lindblad S, Hedfors E: Arthroscopic and immunohistologic characterization of knee joint synovitis in osteoarthritis. Arthritis Rheum 1987, 30:1081-1088

10. Ayral X, Pickering EH, Woodworth TG, Mackillop N, Dougados M: Synovitis: a potential predictive factor of structural progression of medial tibiofemoral knee osteoarthritis - results of a 1 year longitudinal arthroscopic study in 422 patients. Osteoarthritis Cartilage 2005, 13:361-367

11. Benito MJ, Veale DJ, FitzGerald O, van den Berg WB, Bresnihan B: Synovial tissue inflammation in early and late osteoarthritis. Ann Rheum Dis 2005, 64:1263-1267

12. Sellam J, Berenbaum F: The role of synovitis in pathophysiology and clinical symptoms of osteoarthritis. Nat Rev Rheumatol 2010, 6: 625-635

13. Mathiessen A, Conaghan PG: Synovitis in osteoarthritis: current understanding with therapeutic implications. Arthritis Res Ther 2017, 19:18

14. MacFarlane LA, Yang H, Collins JE, Jarraya M, Guermazi A, Mandl LA, Martin SD, Wright J, Losina E, Katz JN: Association of changes in effusion-synovitis with progression of cartilage damage over eighteen months in patients with osteoarthritis and meniscal tear. Arthritis Rheumatol 2019, 71:73-81

15. Felson DT, Niu J, Neogi T, Goggins J, Nevitt MC, Roemer F, Torner J, Lewis CE, Guermazi A: Synovitis and the risk of knee osteoarthritis: the MOST study. Osteoarthritis Cartilage 2016, 24: 458-464

16. Csoka AB, Frost GI, Stern R: The six hyaluronidase-like genes in the human and mouse genomes. Matrix Biol 2001, 20:499-508

17. Yoshida H, Nagaoka A, Kusaka-Kikushima A, Tobiishi M, Kawabata K, Sayo T, Sakai S, Sugiyama Y, Enomoto H, Okada Y, Inoue S: KIAA1199, a deafness gene of unknown function, is a new hyaluronan binding protein involved in hyaluronan depolymerization. Proc Natl Acad Sci U S A 2013, 110:5612-5617

18. Nagaoka A, Yoshida H, Nakamura S, Morikawa T, Kawabata K, Kobayashi M, Sakai S, Takahashi Y, Okada Y, Inoue S: Regulation of hyaluronan (HA) metabolism mediated by HYBID (Hyaluronanbinding protein involved in HA depolymerization, KIAA1199) and HA synthases in growth factor-stimulated fibroblasts. J Biol Chem 2015, 290:30910-30923

19. Abe S, Usami S, Nakamura $Y$ : Mutations in the gene encoding KIAA1199 protein, an inner-ear protein expressed in Deiters' cells and the fibrocytes, as the cause of nonsyndromic hearing loss. J Hum Genet 2003, 48:564-570

20. Evensen NA, Li Y, Kuscu C, Liu J, Cathcart J, Banach A, Zhang Q, Li E, Joshi S, Yang J, Denoya PI, Pastorekova S, Zucker S, Shroyer KR, Cao J: Hypoxia promotes colon cancer dissemination through up-regulation of cell migration-inducing protein (CEMIP). Oncotarget 2015, 6:20723-20739

21. Shimizu H, Shimoda M, Mochizuki S, Miyamae Y, Abe H, Chijiiwa M, Yoshida H, Shiozawa J, Ishijima M, Kaneko K, Kanaji A, Nakamura M, Toyama Y, Okada Y: Hyaluronan-binding protein involved in hyaluronan depolymerization is up-regulated and involved in hyaluronan degradation in human osteoarthritic cartilage. Am J Pathol 2018, 188:2109-2119

22. Altman R, Asch E, Bloch D, Bole G, Borenstein D, Brandt K, Christy W, Cooke TD, Greenwald R, Hochberg M, Howell D, Kaplan D, Koopman W, Longley S III, Mankin H, McShane DJ, Medsger T Jr, Meenan R, Mikkelsen W, Moskowitz R, Murphy W, Rothschild B, Segal M, Sokoloff L, Wolfe F: Development of criteria for the classification and reporting of osteoarthritis. Classification of osteoarthritis of the knee. Diagnostic and Therapeutic Criteria Committee of the American Rheumatism Association. Arthritis Rheum 1986, 29:1039-1049

23. Whelan JA, Russell NB, Whelan MA: A method for the absolute quantification of cDNA using real-time PCR. J Immunol Methods 2003, 278:261-269

24. Takizawa M, Ohuchi E, Yamanaka H, Nakamura H, Ikeda E, Ghosh P, Okada Y: Production of tissue inhibitor of metalloproteinases 3 is selectively enhanced by calcium pentosan polysulfate in human rheumatoid synovial fibroblasts. Arthritis Rheum 2000, 43:812-820

25. Fujita Y, Shiomi T, Yanagimoto S, Matsumoto H, Toyama Y, Okada Y: Tetraspanin CD151 is expressed in osteoarthritic cartilage and is involved in pericellular activation of pro-matrix metalloproteinase 7 in osteoarthritic chondrocytes. Arthritis Rheum 2006, 54:3233-3243

26. Chijiiwa M, Mochizuki S, Kimura T, Abe H, Tanaka Y, Fujii Y, Shimizu H, Enomoto H, Toyama Y, Okada Y: CCN1 (Cyr61) is overexpressed in human osteoarthritic cartilage and inhibits ADAMTS-4 (aggrecanase 1) activity. Arthritis Rheumatol 2015, 67: $1557-1567$

27. Okada Y, Nakanishi I, Kajikawa K: Ultrastructure of the mouse synovial membrane. Development and organization of the extracellular matrix. Arthritis Rheum 1981, 24:835-843

28. Manferdini C, Paolella F, Gabusi E, Silvestri Y, Gambari L, Cattini L, Filardo G, Fleury-Cappellesso S, Lisignoli G: From osteoarthritic synovium to synovial-derived cells characterization: 
synovial macrophages are key effector cells. Arthritis Res Ther 2016, 18:83

29. O'Brien K, Tailor P, Leonard C, DiFrancesco LM, Hart DA, Matyas JR, Frank CB, Krawetz RJ: Enumeration and localization of mesenchymal progenitor cells and macrophages in synovium from normal individuals and patients with pre-osteoarthritis or clinically diagnosed osteoarthritis. Int J Mol Sci 2017, 18:774

30. Goldring MB, Otero M: Inflammation in osteoarthritis. Curr Opin Rheumatol 2011, 23:471-478

31. Wang T, He C: Pro-inflammatory cytokines: the link between obesity and osteoarthritis. Cytokine Growth Factor Rev 2018, 44:38-50

32. Yamamoto $\mathrm{H}$, Tobisawa $\mathrm{Y}$, Inubushi $\mathrm{T}$, Irie $\mathrm{F}$, Ohyama $\mathrm{C}$, Yamaguchi Y: A mammalian homolog of the zebrafish transmembrane protein 2 (TMEM2) is the long-sought-after cell-surface hyaluronidase. J Biol Chem 2017, 292:7304-7313

33. Stern R, Kogan G, Jedrzejas MJ, Soltés L: The many ways to cleave hyaluronan. Biotechnol Adv 2007, 25:537-557

34. Hashizume M, Mihara M: High molecular weight hyaluronic acid inhibits IL-6-induced MMP production from human chondrocytes by up-regulating the ERK inhibitor, MKP-1. Biochem Biophys Res Commun 2010, 403:184-189

35. Livshits G, Zhai G, Hart DJ, Kato BS, Wang H, Williams FM, Spector TD: Interleukin-6 is a significant predictor of radiographic knee osteoarthritis: the Chingford study. Arthritis Rheum 2009, 60: 2037-2045

36. Shimura Y, Kurosawa H, Tsuchiya M, Sawa M, Kaneko H, Liu L, Makino Y, Nojiri H, Iwase Y, Kaneko K, Ishijima M: Serum interleukin 6 levels are associated with depressive state of the patients with knee osteoarthritis irrespective of disease severity. Clin Rheumatol 2017, 36:2781-2787

37. Shimura Y, Kurosawa H, Sugawara Y, Tsuchiya M, Sawa M, Kaneko H, Futami I, Liu L, Sadatsuki R, Hada S, Iwase Y, Kaneko K, Ishijima M: The factors associated with pain severity in patients with knee osteoarthritis vary according to the radiographic disease severity: a cross-sectional study. Osteoarthritis Cartilage 2013, 21: $1179-1184$

38. Zhang YH, Lin JX, Yip YK, Vilcek J: Enhancement of cAMP levels and of protein kinase activity by tumor necrosis factor and interleukin 1 in human fibroblasts: role in the induction of interleukin 6. Proc Natl Acad Sci U S A 1988, 85:6802-6805

39. Fahy N, de Vries-van Melle ML, Lehmann J, Wei W, Grotenhuis N, Farrell E, van der Kraan PM, Murphy JM, BastiaansenJenniskens YM, van Osch GJVM: Human osteoarthritic synovium impacts chondrogenic differentiation of mesenchymal stem cells via macrophage polarisation state. Osteoarthritis Cartilage 2014, 22: $1167-1175$

40. Mimata Y, Kamataki A, Oikawa S, Murakami K, Uzuki M, Shimamura T, Sawai T: Interleukin-6 upregulates expression of ADAMTS-4 in fibroblast-like synoviocytes from patients with rheumatoid arthritis. Int J Rheum Dis 2012, 15:36-44

41. Latourte A, Cherifi C, Maillet J, Ea HK, Bouaziz W, FunckBrentano T, Cohen-Solal M, Hay E, Richette P: Systemic inhibition of IL-6/Stat3 signalling protects against experimental osteoarthritis. Ann Rheum Dis 2017, 76:748-755

42. Tsuchida AI, Beekhuizen M, Rutgers M, van Osch GJVM, Bekkers JEJ, Bot AGJ, Geurts B, Dhert WJA, Saris DBF, Creemers LB: Interleukin-6 is elevated in synovial fluid of patients with focal cartilage defects and stimulates cartilage matrix production in an in vitro regeneration model. Arthritis Res Ther 2012, 14:R262

43. Ito T, Ikeda U, Shimpo M, Yamamoto K, Shimada K: Serotonin increases interleukin-6 synthesis in human vascular smooth muscle cells. Circulation 2000, 102:2522-2527

44. Donnelly RP, Crofford LJ, Freeman SL, Buras J, Remmers E, Wilder RL, Fenton MJ: Tissue-specific regulation of IL-6 production by IL-4. Differential effects of IL-4 on nuclear factor-kappa B activity in monocytes and fibroblasts. J Immunol 1993, 151:5603-5612 